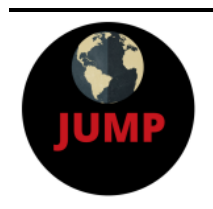

ISSN: 2574-3465 Print/ ISSN: 2574-3481 Online

Volume 2, Issue 1 (2018), pp. 44-72

(c) Journal of Underrepresented and Minority Progress

http://minorityprogress.org/ doi: 10.5281/zenodo.1322163

\title{
The Academic Success of African American Males at a Maryland Community College
}

\author{
Joel Bratton \\ Morgan State University, USA
}

\begin{abstract}
The purpose of this qualitative study is to examine the perception of African American males participating in one 4A program at a Mid-Atlantic community college. Twenty African American males, along with six staff members were selected to participate in the study. The study used focus groups to investigate students' interactions with academic advisors and counselors and the impact of those interactions on students' academic success. The nigrescence theory of evolving cultural identity served as the framework, as it emphasizes the role and impact of cultural identity as a driver for successful academic performance (Cross, 1991). The study revealed that these African American males had positive perceptions of their experiences in the program and with their mentors, advisors, and counselors.
\end{abstract}

Keywords: African American males, community college, academic success

\section{INTRODUCTION}

The traditional mission of the community college has been to provide access to higher education (Kolesnikova, 2009; Nettles \& Millette, 2013). To be true to its name and its mission, community colleges are focused on the nature and diversity of the communities in which they are located. As colleges continue to address the needs of increasingly diverse populations, meeting the needs of African American males has been historically difficult relative to accessing higher education, achieving academic success and/or persisting to graduation. Community colleges were designed to address issues of racial, ethnic, economic, and religious inequality in higher education as detailed in the 1947 Truman Commission report, which directed states to remedy those inadequacies through educational access, equity, and service. Although these colleges evolved out of that directive, progress has not been as pervasive as hoped. Continuing issues negatively impact the retention and graduation of African American males in higher education (Zell, 2011). Many researchers have questioned whether community colleges have alleviated these issues (e.g., Beckles, 2008; Freeman, 2003; Glenn, 2003; Ihekwaba, 2001; Mason, 1994, 1998; Riley, 2007; Scaggs, 2004; Travis, 1994). 


\section{LITERATURE REVIEW}

\section{Minority Students in Community Colleges}

Community colleges have become popular among several groups of students. The examination of data emerging from various student cohorts who have chosen to attend community colleges to receive degrees or to transfer to 4-year colleges and universities, provides an interesting landscape. In recent decades, recruiters in higher education have placed enormous emphasis on recruiting minority students. Between 1995 and 2009, enrollment among freshman doubled for Hispanics, increased 73\% for African Americans, and rose 15\% for Caucasians (Fletcher, 2013). Although enrollment figures for minority students may appear impressive, retention and graduation rates fail to reflect this surge in numbers. Despite the pivotal role community colleges play in promoting social equality, they continue to face challenges related to low persistence and retention rates among minority males.

In fact, only $15 \%$ of Hispanic students and $14 \%$ of African American students ever graduate from community college after three years of matriculation (Tyler, Sterling, \& Grays, 2013). Recruiting and graduating African American and Hispanic males poses a significant challenge for community colleges. Literature often describes minority males as a segment of the community college environment that has poor academic preparation in high school, minimal achievement in college, and low self-concept (Tyler et al., 2013). Community colleges across the country have, for example, developed Minority Males Initiatives. These programs were created to improve the academic success rate of minority males in higher education (Tyler et al., 2013). However, there are several factors that prevent minority students from advancing to 4-year colleges.

Specifically, the cost of attending 4-year colleges is too high for most households, and federal student aid has become more difficult to obtain. A recent report indicated that more than $69 \%$ of minority students who quit college did so because of federal loan debts. Additionally, minority students are discouraged from continuing their education to 4-year colleges because of lack of such institutional services to support their academic needs (Nunez, 2013). Similarly, Greene (2008) examined student engagement to determine the extent that it impacted the success rate of minority students in community colleges. The study revealed that minority students are at greater risk of struggling in college compared to their Caucasian counterparts. Engagement was defined as the effort expended by students and the institutional environment, which may or may not have a positive impact on students' decision to remain in college. African Americans with a high level of engagement struggled in community colleges. Greene (2008) concluded that minorities must increase their engagement in community colleges in order to overcome risk factors and academic weaknesses. McClenney and Greene (2005) asserted that contemporary colleges must redesign minority students' educational experiences and enhance institutional practices in order to improve persistence rates. Given the fact that community colleges have become the college of choice for many minority students, policymakers may find it advantageous to invest in them, for they may hold the key to future economic success in America (McIntosh, 2009).

\section{Community Colleges and Black Male Success}

Beckles (2008), Bush (2004), and Jordan (2008) found that community colleges face unique challenges when trying to promote the academic and social integration of students. Unlike residential campuses, the community college environment has many distractions related to work, family, and relationships with people outside the academic community (Bush, 2004; 
Dabney, 2012; Jordan, 2008). Moreover, community college students tend to spend less time interacting with fellow students and faculty outside the classroom. These factors may limit the extent to which community colleges provide a collegiate experience that effectively shapes their goals and aspirations. This reality may pose significant challenges for any efforts to promote academic success for African American males at community colleges. It is worth noting that many of the models for promoting African American male academic achievement include in their design attention to the areas of academic and social integration (Freeman, 2003; Tinto, 1993; Wood, 2010).

Unlike 4-year institutions, community colleges enroll African American men in larger numbers compared to other ethnic/gender groups. However, community colleges' success with African American males is disappointing. Despite their relatively large African American male presence, community colleges have not been able to produce African American male graduates or transfer students at the same rate as their counterparts within other demographic groups (American Council on Education, 2006). According to Freeman (2003), African American males constitute the only ethnic/gender group with less than $50 \%$ first-year persistence. Dickens' (2012) study explored factors impacting the persistence of male African American community college students and found that four major factors positively influence persistence among African American community college students. Those four major factors that positively influence persistent among African American male students are: family involvement, school as a priority, teacher mentoring, and community membership. The study's finding also indicated that stereotypes and self-sufficiency were identified by African American male subjects as the most common barriers to persistence, pointing to a need for multiple countering strategies for overcoming these obstacles.

Scholars have noted that student success is a core component of the community college mission. Bush (2004) purported that community colleges have failed to facilitate African American males' livelihood and upward mobility, which comprises this failure of mission. Beckles (2008) noted that students perceived that a desire to prove wrong those who may not have faith in their ability to succeed leads to academic success. Overall, a mindset of dedication to succeed was identified as leading to academic success (Beckles, 2008; Faison, 1993; Perrakis, 2008). Similarly, Perrakis (2008) found that as student dedication to persistence improved, so did grade point averages. Research has also illustrated the importance of peers in positively and negatively impacting academic success (Beckles, 2008; Fiason 1993; Jordan, 2008). While Beckles (2008) noted that peers served as a source of support for academic success, Faison (1993) identified a negative correlation between group dependence and academic achievement.

However, Jordan (2008) noted that students identified peer group relationships as positively affecting their success. Students identified relationships with peers, faculty, and other administrators as having the most effect on their academic success. These positive relationships centered on academic activities like study groups and tutoring as factors in student success. While faculty and peer relationships have been identified, several scholars noted that family support and encouragement were also important (Beckles, 2008; Hampton, 2002; Mosby, 2009). Hampton (2002) noted that students with higher family support achieved a higher gradepoint average. Mosby (2009) noted that parents and family influenced students' desire to attend college, their goals in college, and their aspirations to continue toward identified career goals.

There are many studies that point to statistics regarding African American males and their educational struggles, but only a few studies place emphasis on the academic success of African American men in college. Hughes (2010) highlighted a summer bridge program patterned after the Student African American Brotherhood (SAAB), a national program to 
foster the academic achievement of African American males. The program was structured on three design elements - heterogeneous and homogeneous balance, African American male mentoring, and anticipatory advising. Most notably, this study revealed that mentorship and proactive counseling proved to be motivating factors for successful matriculation and higher academic aspirations for African American males.

The African American Male Initiative (AAMI) was created to improve the success rate of African American male college students. The United States Department of Education awarded grants to hundreds of colleges across the country, many of which were community colleges. The St. Louis Community College, for example, noted several goals created as a result of the grant: increase the persistence rate of African American males, achieve academic achievement levels, and educate faculty members and staff about the array of challenges African Americans experience when they enroll in community college. Each participant is assigned a mentor to help him cope with the realities of college.

Additionally, the program provides tutoring services, academic monitoring, and stipends for students in need of financial assistance, and referrals to community organizations (St. Louis Community College, 2013). Wood (2011) provided a different perspective on academic success in reference to African American males. Wood indicated that the success rate of African American males at community colleges should be measured by the graduation rates, whereas most studies focus on retention rates. The difference is that students can stay in college for many years and make minimal academic progress. Graduation rates, on the other hand, are more indicative of academic success for African American men because they reveal what students have achieved during their college years. Graduation rates provide the data needed to determine the impact of community colleges on the lives of African American male students and they also help to set benchmarks needed to assess effectiveness.

\section{Socioeconomic Factors and Student Persistence}

Tinto's (1993) work has been widely used to explain the social challenges African American students face in persisting in college. According to Tinto, when African American males have not been adequately socialized or integrated into the college environment, they depart without completing their college education. Tinto asserted that African American males' commitment to the institution influences their motivation to become engrossed in learning and interest in attaining a college degree. Moreover, Tinto argued that African American males have little influence on socioeconomic factors such as finances, external peer pressures, and the learning environment. Although the focus of Tinto's study was on traditional 4-year institutions of higher learning, the model has application to community colleges as well (Jordan, 2008).

Research has suggested that when social factors are considered along with economic factors, challenges faced by African American males become more pronounced. That is, African American males are confronted with socio-economic issues that threaten their ability to flourish in a competitive society (Dabney, 2012). For example, African American males must rely on financial support from their families and financial aid in order to attend college. In many cases, African American males who aspire to attain a college degree do not receive scholarships unless they are athletes. They may also come from low-income homes where family members may not stress the importance of a college education. Moreover, African American males have to choose between going to college or getting a job and contributing to their family income (Owens, Lacey, Rawls, \& Hulbert-Quence, 2010).

Research has also shown that many African American males are often first-generation college students whose parents may not have an appreciation for a college education as compared to those parents who are college graduates (Owens et al., 2010). When the 
importance of a college education is not emphasized in African American homes, children reared in those homes are less likely to aspire to attend college (Owens, et al., 2010; Perry, 2004). A lack of support from the home, coupled with negative stereotypical perceptions of African American males, places them at higher risk of experiencing academic and socioeconomic problems throughout their lives (Johnson, 2010). Most of them do poorly in high school and show no interest in pursuing higher education because of the lack of support they receive from family members.

Conversely, African American males who experience a sense of social belonging and positive influence from individuals in their environment excel academically, regardless of their socio-economic status (Bush, 2004). Harper (2006) asserted that social reinforcement of racially oppressive assumptions eventually impacts the psyche of African American males who have been given the wrong idea as to what it takes to be a man. Some African American males are reared to believe that excelling in school is a White behavior that is frowned upon in African American culture. Many of these males need positive role models in their lives. Positive influence from same-race peers has been found to help African American males overcome misconceptions about higher education and propel them to take on leadership roles in college and beyond their college years (Harper, 2006).

\section{Academic Factors and Student Persistence}

The academic achievement gap bogging down African American males on all educational levels is well documented in the literature (Bush \& Bush, 2010; Dabney, 2012; Walters, 2013). African American males' low enrollment, disengagement, and low graduation rates are some of the most critical issues facing higher education (Harper, 2014). Concerning community colleges, African American males have the lowest graduation rates among their racial/ethnic counterparts. In fact, only $12 \%$ of African American males graduate after three years of study compared to $23 \%$ of Asian males, and nearly $24 \%$ of Caucasian males. Additionally, African American males in community colleges are generally older and have family obligations that distract from their college work (Wood, 2012). When attending community colleges, Black males are also less likely to discuss their academic problems with faculty members outside of the classroom. Those who choose to seek faculty members' feedback are much more likely to persist than those who choose not to seek feedback from faculty (Bush, 2004; Bush \& Bush 2010).

A number of studies have focused on the academic skills of African Americans prior to enrolling in college (Dabney, 2012). One report consisting of responses from 145,000 male community college students indicated that even when African American males participate in tutorials and orientation, they experience less academic success than their college counterparts. Moreover, only five percent of African American males earn college degrees after three years of study at community colleges compared to $32 \%$ of White men (Mangan, 2014). For years, studies have shown that African American male students are not given the same educational enrichment opportunities as other students.

They are disproportionately placed in special education using inappropriate practices and policies, and they are punished more severely than White students who commit the same infractions. In addition, more than twice as many White male students are given extra resources than African American male students. Only a token number of African American males are enrolled in advanced placement classes and in some college preparatory schools it is not uncommon to find virtually no African Americans males enrolled (Schott Foundation for Public education, 2010). Black male students who eventually graduate from high school and enroll in community colleges have high aspirations for themselves compared to their White 
male counterparts, but studies show that given the barriers they face, they are still less likely to be successful (Mangan, 2014).

\section{Institutional Factors and Student Persistence}

Institutional characteristics also impact the academic persistence of African American males in higher education (Bush \& Bush, 2010). For instance, several authors have noted the importance of a supportive environment cultivated by faculty, advisors, and other personnel (Beckles, 2008; Bush, 2004; Jordan, 2008). Jordan's (2008) study analyzed the factors of students' perception of academic success and found that students believed they were more successful when faculty interacted with them and listened to their concerns. Bush and Bush (2010) also noted that institutional factors are important in improving the retention rate of African American males. The researchers asserted that some of the steps community colleges can take to improve retention include:

- Develop programs that address the specific needs of African American male students.

- Assign faculty mentors to each African American male enrolled in the college.

- Provide adequate orientation to African American males upon arriving on campus.

- Employ faculty and staff members who are interested in improving the success rate of African American males.

- Develop small learning communities for African American males.

- Encourage instructors to include the contributions of African American males in their lessons.

- Develop campus-wide activities that attract African American males to college culture.

- Pair African American male freshmen with students who have been successful in college and are close to graduating.

Brown (2009) pointed out that African American males need communities comprised of men who can ensure their safe passage and celebrate their achievements through adulthood. African American males appreciate faculty mentors who are involved in their academic lives, in addition to support groups that help to ease their transition into college. Institutions that focus on providing opportunities for students to build strong personal relationships on campus, as well as instructors dedicated to student achievement and engagement, are likely to be more effective in retaining and graduating African American males (Mangan, 2014). Similarly, Evans (2010) noted that institutions of higher learning that offer programs and services to help develop the academic and social skills of African American males are more successful in retaining them. Evans suggested that institutions focus on providing opportunities for student affairs professionals to proactively identify and address student needs, design academic and social programs, develop policies, and create healthy college environments that foster growth and development among students. Additionally, Alfred (2009) noted that institutional characteristics should consist of a curriculum and climate inclusive of the academic contributions of Black Americans in order to foster the success of African American males.

\section{The Development of Mentoring Programs}

To curtail the negative impact that socio-economic factors have on the persistence rate of African American males, mentoring programs were created in community colleges. Studies 
on the effectiveness of college mentoring programs have been limited in regard to best practices that engage African American males in social experiences that would lead to college success. However, some valuable insight can be garnered from existing literature. A national study conducted by ACT (2010) found that mentoring programs designed to improve the college persistence rate of African American males had a positive impact on their college experience and resulted in an increased number of African American males interested in completing their college education.

Mentoring programs have been found to help African American males to better understand their roles as college students (Kingsbury, 2007) and encourage a sense of belonging and membership within institutions of higher learning (Harper \& Quaye, 2007). Similarly, in conducting an analysis of cross cultural relationships, Baker (2007) noted that mentoring programs had a positive impact on student persistence and college completion among students, regardless of their ethnicity. Baker also stated that mentoring programs increase faculty-student interactions and provide greater access to resources related to career placement for African American students. A similar contention was made by Carson (2009), who noted a sense of increased connectedness among African American males who participated in college mentoring.

Gray (2011) discussed a number of successful college mentoring programs throughout the United States. Specifically, mentoring programs in New York and Georgia were identified as programs that helped to improve the academic success rate of African American males. In the state of Georgia, 19 colleges have implemented African American male initiatives responsible for increasing African American enrollment by 25\% (Schmidt, 2008). Moreover, in New York, 26 African American male mentoring initiatives have been created since 2004. The primary goal of each was to keep African American males engaged in social activities that support positive academic outcomes.

It has been found that New York's college mentoring programs have positive immediate and long-term benefits for African American males (Gray, 2011). Gray expressed the importance of fraternities to become directly involved in mentoring college males. The researcher noted that mentoring should provide hope in the midst of academic challenges. Additionally, mentoring should afford students opportunities to ask questions honestly and provide a place where African American males can express their fears openly and dream about a better life (Gray 2011). Edelman, Holzer, and Offner (2006) asserted that African Americans have greater satisfaction with their college experience when they participate in mentoring. Mentors help to guide African American men through critical points of the educational, professional, and personal development. In many college mentoring programs, African American male mentees are matched with African American mentors who have faced the same social challenges. The relationship formed between the mentor and mentee helps African American males to feel that the mentors understand the issues that confront them on college campuses. Hence, these factors comprised a social support system that positively impacted the college success of rate of African American males (Brown, 2009).

The Dellums Commission (2004) conducted a study that involved 50 flagship colleges and universities. The Commission noted that African American males made up less than 2.4 percent of the undergraduate enrollment of colleges included in the study. The study found that mentoring programs and similar initiatives are essential in improving the college retention rates of African American males. Such programs can play important roles in recruiting, encouraging, and tracking the academic progress of African American male participants. Brown (2009) identified several mentoring programs that have had measurable success in improving college 
enrollment and graduation rates of African American male students. Notable programs included the following:

- The Black Man's Think Tank is an initiative at the University of Cincinnati that provided a forum for African American males to express their concerns and address issues related to their academic and social experiences in higher education.

- The Student African American Brotherhood was founded at Georgia Southern University. One of the key goals of the organization was intervention and support for African American male students facing academic challenges and to help them appreciate the importance of being responsible citizens.

- The Black Male Initiative was established in 1990 at Texas Southern University, this program provided role models for entering college students. The primary objective of the program was to teach value education.

- The Meyerhoff Program was founded at the University of Maryland, Baltimore, this program aimed to increase the number of males who earned doctorates.

- The Bridge: This initiative provided faculty mentors for African American male students. The goal of the program was to provide enrichment experiences for African American male freshmen.

Black male college students appreciate learning environments that provide academic guidance, peer support, and opportunities for them to express their concerns. Mentoring programs can help to level the playing field in higher education. As a small learning community, mentoring programs are instrumental in addressing academic and social barriers faced by African American males at community colleges (Jordan, 2008).

\section{Racial Identity Development}

Consistent with the historical and current emphasis placed on race within U.S. society, racial identity has been deemed a significant and influential factor for human development (Worell \& Gardner-Kitt, 2006) and is now a widely accepted construct within psychological literature (Carter, Pieterse, \& Smith, 2008). In fact, racial identity is perhaps the most significant dimension of African American life and functionality (Scott, 2003). Racial identity is defined as the significance and meaning of race to an individual's self-concept (Rowley, Burchinal, \& Zeisel, 2008; Sellars, Rowley, Chavous, Shelton, \& Smith, 1997). Some scholars have contended that racial identity is a construct inherently distinct from ethnic or cultural identity; whereas, ethnic or cultural identification may be covert and may vary over time, race, for the most part, remains overt and constant (Burrow, Tubman, \& Montgomery, 2006). Racial identity includes but is not limited to, the extent to which an individual defines himself or herself in terms of race (racial centrality), one's sense of pride in group membership and evaluation of the relative merits of the group (private regard), and beliefs about how others view the group (public regards) (Rowley et al., 2008). Typically ascribed to individuals belonging to historically marginalized racial groups, the process of racial identity development is thought to be influenced by several factors, including an individual's internalized social prejudices and racism (Worrell \& Gardner-Kitt, 2006).

The significance of racial identity development has been discussed extensively in the literature, and it seems that racial identity development has been universally deemed as important, particularly for African Americans. There is some debate as to exactly how racial identity is important. Racial identity has consistently been a conceptualized linked with the 
psychological functioning of African Americans (Azibo, 1983; Cross, Parham, \& Helms, 1998; Parham, 1989) and has been conceptualized as having both a direct and an indirect link to psychological well being (Sellers, Copeland-Linde, Martin, \& Lewis, 2006). Some have asserted that the empirical evidence for the direct link between racial identity and psychological functioning is inconclusive. Others have argued that a strong identification with being Black and embracing a definition of Blackness that focuses on a specific African value orientation is a necessary component of healthy psychological functioning among African American (Sellers et al., 2006). Positive racial identity has been empirically linked to increased psychological adaptation and functioning, increased self-esteem and achievement (Carter, 1991; Parham \& Helms, 1985; Thomas \& Speight, 1991; Ward, 1990).

Negative racial identity in African Americans has been theoretically linked to low selfesteem, problems with psychological adjustments, low school achievement, dropout tendencies, teenage pregnancy, gang involvement, eating disorders, drug abuse and involvement in crime. Due to the possibility of a negative racial identity, it is important that African Americans develop a positive sense of racial pride (Thomas \& Speight, 1989). Several theories of racial identity development have been put forth to articulate the process by which individuals develop attitudes and beliefs regarding the importance and meaning of the racial group membership (Seaton, Scottham, \& Sellars, 2006). William Cross, PhD contributed to defining the process of racial identity.

Cross's original theory of racial identity consisted of five stages such as, (a) Preencounter, (b) Encounter, (c) Immersion-Emersion, (d) Internalization, and (e) InternalizationCommitment. In the first stage, pre-encounter, the individual's worldview is observed by EuroAmerican determinants (Cross, 2001). Individuals in the pre-encounter stage have low salience to race or may have strong anti-Black and pro-White feelings. During stage two, the encounter stage, the individual may encounter a shocking personal or social event that temporarily dislodges the person from his or her old worldview, making the person receptive to a new interpretation of his or her identity or condition (Cross, 2001).

The experience that occurs during the encounter stage may cause individuals to challenge their previously held beliefs; individuals may experience feelings of confusion, alarm, and depression followed by guilt, anger, and anxiety (Cross, 2001). In immersion, the third stage, individuals immerse themselves in Afrocentric culture, including values, beliefs and activities. This stage is characterized by intense feelings of anger. In the fourth and fifth stages internalization and internalization-commitment, individuals have internalized their racial identity with their self-concept.

The internalization stage signals the resolution of conflicts between the "old" and "new" worldviews. Ideological flexibility, psychological openness, and self-confidence about one's Blackness are evident in interpersonal transactions. Anti-White feelings decline to the point where friendships with White associates can be renegotiated. While still using Blacks as a primary reference group, the person moves towards a pluralistic, non-bigoted perspective (Cross, 2001). The fifth stage, internalization-commitment, is characterized by political activity to end oppression for all people.

A second noteworthy theory of Black racial identity development is the Multidimensional Model of Racial Identity (MMRI) (Sellers, Smith, Shelton, Rowley, \& Chavous, 1998). The MMRI defines racial identity in African Americans as significant and qualitative, meaning individuals attribute to their membership within the Black racial group within their self-concepts. This definition can be broken into two questions: How important is race in the individual's conception of self? and What does it mean to be member of this racial group? The MMRI attempts to answer these questions (Sellers et al., 1998). With these 
questions in mind, four assumptions serve as the foundation for the MMRI. First, the MMRI assumes that identities are situationally influenced as well as being stable properties of the person. The MMRI takes a position similar to that of Stryker and other identity theorists, in that the identity has both properties (Sellers et al., 1998; Stryker \& Serpe, 1982, 1994).

Specifically, racial identity in African Americans has dynamic properties that are susceptible to contextual cues, allowing the stable properties of identity to influence behavior at the level of the specific event. At the same time, there are also stable properties of racial identity that allow observance of differences in qualitative value and the significance individuals place on the role race influences how they define themselves (Sellars et al., 1998). A second assumption of the MMRI is that individuals have several different identities and that these identities are hierarchically ordered (Sellers et al., 1998; Stryker \& Serpe, 1982, 1994). Although a number of different criteria can be identified in the literature as placing various identities within a hierarchy, the MMRI uses criteria that are most consistent with those used by Rosenberg (1979).

\section{METHODOLOGY}

This study used a qualitative design to understand how African American males in the 4A program at a community college in the Mid-Atlantic region extract "the rich component and deeply rooted self-practices" of African American male students (Merriam, 2011). Based on the literature reviews it does seem like there is plenty of work to be done in terms of creating a better understanding of male initiative programs. The three research questions that guided this study were as follow:

1. How do African American males describe their experiences in the 4A program?

2. What evidence of cultural identity development will the narrative of experience reveal?

3. What is the perception of mentors, advisors, and counselors of their influence on African American males?

\section{Participant Selection}

The college selected for this study is a community college in the Mid-Atlantic region that has served its urban area for almost 70 years. The community college has a population of approximately 7,000 students-more than 4,800 women and 2,500 men from diverse cultural, educational, religious, and socio-economic backgrounds. Almost $70 \%$ of its student population is African American and of that group. The majority has a family income of under $\$ 25,000$.

While enrolled at this college in the Mid-Atlantic region, students can participate in several academic and social programs. The 4A Program operates to undergird the lives of African American males by providing them with a number of opportunities to become academically successful. The 4A Program offers several services to African American male students: mentoring, discussion groups, workshops, enrichment sessions, tutoring, motivational speakers, field trips, and academic advisement. The following conceptual model illustrates the experiences and services rendered by the 4A Program to achieve positive academic outcomes: 


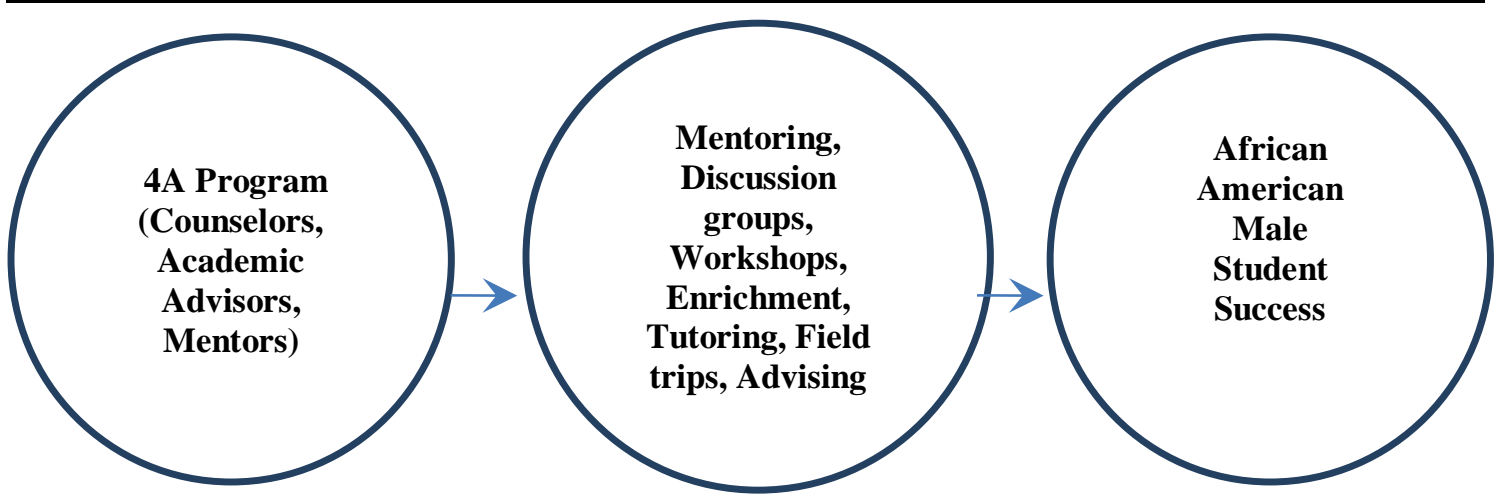

As illustrated in the above diagram, counselors, academic advisors, and mentors play a key role in determining the success of the 4A Program. They are responsible for engaging in research-based strategies that they believe will result in the success of African American males at the selected community college. The researcher was invited by the director to visit him to discuss this study. He provided an overview of the 4A program at a Mid-Atlantic region community college, sharing details about the program and how it came into existence.

The director also provided a list of the participants' contact information, which included emails and contact numbers. In addition, the researcher received a schedule of events in which the students participated, such as rap sessions and outings. The researcher contacted each student individually to extend an invitation for the students to participate in the study. Students were also given a recruitment that provided the researcher's contact information. Twenty of the 80 students enrolled in the 4A program participated in the focus group. The criteria for their selection were as follows: at least eighteen years of age, currently enrolled at the college, participating in the $4 \mathrm{~A}$ program at the college for at least one semester, and a demonstrated a willingness to participate in a focus group. Many of the students received encouragement to participate from their mentors, advisors, and counselors associated with the 4A program.

Participants selected for the study were identified as African American males of U.S. citizenship, between the ages of 18 and 64, representing the general population of the 4A program. The 20 participants were enrolled full time at a college in the Mid-Atlantic Region. Each participant completed an informed consent form. Based on the consent forms, the remaining students were not chosen for the study because they were not fully engaged in the program. Participants were selected by academic advisors and counselors. During the initial meeting, eligible participants provided their consent forms to participate in the study. There were no limitations in the sample selection that limited the study.

\section{Study Participants}

The student demographic questionnaire revealed characteristics of the members of three focus groups comprised of 20 African American males from a community college in the Mid-Atlantic region of the United States. Nine participants completed one semester of coursework, and six participants completed two semesters of coursework. The remaining five participants completed more than two semesters of coursework and were within a year of graduating. Fourteen of the 15 students graduated from high school in urban areas, two of them graduated from suburban high schools, and four graduated from rural high schools. Among the group of participants were two out-of-state participants, both from suburban areas (Table 1).

Table 1. Demographic profile of participants. 


\begin{tabular}{lccc}
\hline Participant & Age & Academic Classification & Major \\
\hline Participant 1 & 19 & Sophomore & General Studies \\
Participant 2 & 29 & Sophomore & General Studies \\
Participant 3 & 19 & Sophomore & General Studies \\
Participant 4 & 41 & Sophomore & General Studies \\
Participant 5 & Sophomore & General Studies \\
Participant 6 & 19 & Sophomore & General Studies \\
Participant 7 & 21 & Sophomore & General Studies \\
Participant 8 & 19 & Sophomore & General Studies \\
Participant 9 & 22 & Sophomore & General Studies \\
Participant 10 & 64 & Sophomore & General Studies \\
Participant 11 & 21 & Sophomore & General Studies \\
Participant 12 & 21 & Sophomore & General Studies \\
Participant 13 & 19 & Sophomore & General Studies \\
Participant 14 & 19 & Sophomore & General Studies \\
Participant 15 & 19 & Sophomore & General Studies \\
Participant 16 & 24 & Sophomore & General Studies \\
Participant 17 & 19 & Sophomore & General Studies \\
Participant 18 & 18 & Sophomore & General Studies \\
Participant 19 & 26 & Sophomore & General Studies \\
Participant 20 & 19 & Sophomore & General Studies \\
\hline
\end{tabular}

\section{Participant 1}

Participant 1, from Baltimore, Maryland, was enrolled in general studies. He graduated from the Baltimore City Public School system with a 2.5 grade point average. He grew up in an ethnically diverse community, which consisted of families that were socio-economically poor and middle class. He enjoys playing sports, listening to hip hop music and being member of the basketball team.

\section{Participant 2}

Participant 2 was taking General Studies courses. He is also from Baltimore, Maryland and graduated from the Baltimore City Public School system with a 2.0 grade point average. He grew up in a poor neighborhood. Participant Two enjoys playing basketball, working out, and listening to hip hop music. He is also involved in extra-curricular activities.

\section{Participant 3}

Participant 3, also a General Studies major, is from Baltimore, Maryland and graduated from Baltimore City Public Schools. He experienced racial tension throughout high school. He also encountered personal struggles with his own racial identity. The community in which he was raised was racially diverse. He likes hip-hop music and playing sports. He had a 2.1 grade point average.

\section{Participant 4}

Participant 4 was majoring in General Studies and is also from Baltimore, Maryland. He attended Baltimore City Public Schools and lived in a Black middle-class area. Like many African American males, he likes reading, playing sports, and playing video games. He had a 2.5 grade point average. He was actively involved on campus. 


\section{Participant 5}

Participant 5, a General Studies major as well, is from Baltimore, Maryland and attended Baltimore City Public Schools. He was not the best student academically in high school. He lived in a poor area of the city. His grade point average was 2.0. He likes playing sports, listening to music, and playing video games. He participated in on-campus activities.

\section{Participant 6}

Participant 6 was taking General Studies courses. He was from Baltimore, Maryland and attended Baltimore City Public Schools. He also participated in sports and was involved with activities at school. His grade point average was a 3.0. He came from a diverse community in Baltimore and experienced racism while in high school, which he again experienced on the college campus with one of his instructors. He enjoys reading and riding motorcycles.

\section{Participant 7}

Participant 7 was taking General Studies courses. He was from the suburban area of Delaware and lived in a diverse community. He experienced racism in his neighborhood. Participant Seven has consistently been involved in sports and played basketball during his college career. His grade point average was a 2.5 . He likes to read and interact with the students on campus.

\section{Participant 8}

Participant 8 was taking general studies course. He was raised in a poor neighborhood in city of Baltimore. He struggled during high school and needed assistance to maintain his grades. His grade point average was 2.2 . He was a basketball player and was nearly dismissed from the team due to his grades. He likes playing video games, interacting with the student body, and exercising.

\section{Participant 9}

Participant 9 is from Baltimore, Maryland and attended a Baltimore City public school. He lives in a drug-infested area. Although he played sports in high school, he struggled academically. At the time of the study, he was having academic issues. His grade point average is a 2.0. He likes playing video games and listening to rap music.

\section{Participant 10}

Participant 10 is from a suburban area in Philadelphia and pointed out that he experienced racism. He is an athlete and likes to read, work out, and listen to rap music. His grade point average is a 2.5 . He is an average student but is a hard worker and was looking forward to going to a 4-year college.

\section{Participant 11}

Participant 11 is from a rural area in Maryland. He experienced racism from people in his community. He is a good student whose grade point average is 3.0. He likes to read, play video games, and bowl and he was thrilled to attend a school in Maryland. However, he did experience racism amongst some of his professors. He has a clear vision for life.

\section{Participant 12}

Participant 12 is from Baltimore, Maryland. He attended a Baltimore City public school. His academic performance was average in school; however, he is looking forward to 
transitioning to a four-year college. His grade point average is a 2.5. He likes to read and play video games. He enjoys meeting new friends and is involved in many student activities.

\section{Participant 13}

Participant 13 is from a rural area in Maryland. He did well in school and was a student athlete. He never experienced racism; however, some of his friends and parents have experienced racism. It was a breath of fresh air to attend a school in an urban setting. His grade point average was a 3.0. He indicated that he interacted with and participated in many of the clubs.

\section{Participant 14}

Participant 14 lived in a rural area of Maryland and has experienced racism. However, he was glad to leave his hometown and vowed not to return. He was ready for his life to blossom. His grades were good, resulting in cumulative grade point average of a 3.0. He was looking forward to attending a four-year college. He likes reading, rap music, working out, and video games.

\section{Participant 15}

Participant 15 lives in Baltimore, Maryland. He attended Baltimore City Public Schools and his grades were average in high school. The main purpose of him attending a 2year college was to improve his grades. His grade point average is a 2.5. He likes to workout, read, and volunteer. He participates in many of the school social programs.

\section{Participant 16}

Participant 16 comes from a rural area of Maryland. He was raised in a military family. His grades were good in high school, where he participated in sports. He was looking forward to getting away from the area. He likes to ride motorcycles, read, travel, exercise, play video games, and work on computers. His grade point average is 3.0.

\section{Participant 17}

Participant 17 is from Baltimore, Maryland. He was educated in the Baltimore City Public Schools. He was an average student. The community where he was reared was not that well off financially. He played sports. He had a 2.7 grade point average. He enjoys listening to music, playing sports, and reading. He is involved in various student activities.

\section{Participant 18}

Participant 18 is from Baltimore, Maryland and graduated from the Baltimore City Public School system. He had a 2.5 grade point average. The community he grew up in was ethnically diverse and consisted of both poor and middle-class families. He enjoys reading, playing video games, exercising, and interacting with his friends. He participated in several student-run organizations.

\section{Participant 19}

Participant 19 is from Baltimore, Maryland and graduated from a Blue-Ribbon Baltimore City Public school. His grade point average was 2.7 . He knows he is going to be successful. He grew up in a poor area and played basketball in high school. He enjoys reading, playing video games, watching movies, and skateboarding. He is very active on campus and 
participates in many of the student driven campus activities and speaks out against violence and racism.

\section{Participant 20}

Participant 20 is from Baltimore, Maryland and graduated from the Baltimore City Public School system. His community is represented in two economic bases: poor and wealthy. He indicated that he has experienced racism. He has participated in sports all his life. He enjoys learning, reading, traveling, and basketball.

\section{Procedure}

The primary source of data for this study was gathered through focus groups with African American males in the 4A program. The general data collection consisted of the student profile/demographic information sheet. Semi-structured interviews lasted one to two hours, with the majority of the focus groups averaging 60-90 min. Using a series of structured, semi-structured, and open-ended interview questions, allowed the researcher to gain the students' perception of the 4A program, including positives and challenges of the program. All interviews were conducted on campus in a "quiet area" such as the classroom to afford the participants confidentially and good audio quality for taping the conversations. During the focus groups, the researcher used a high-quality tape recorder and a transcriber from the Baltimore City Courts. The clerk's office was given pseudonyms of the participants to assist in transcribing the interviews.

\section{Focus Groups}

Traditionally, focus groups research is "a way of collecting qualitative data, which essentially involves engaging a small number of people in an informal group discussion(s), 'focused' around a particular topic or set of issues" (Wilkinson, 2004, p. 177). The rationale for using the focus group approach was to yield diversity in information from the twenty participants and the six administrators. Including too many participants can create an environment in which participants do not feel comfortable sharing their thoughts, opinions, beliefs and experiences. Krueger (1994) has endorsed the use of very small groups, what he terms "mini- focus groups (p.17) which includes three (Morgan, 1997) or four (Krueger, 1994) participants, when participants have specialized knowledge and/or experiences to discuss in the group. The researcher utilized the classroom at the school where the students felt comfortable participating in a focus group. It was the same room used for each focus group because using multiple focus groups allowed the researcher to assess the extent to which saturation (cf. Flick 1998; Lincoln \& Guba, 1985; Morse, 1995; Strauss \& Corbin, 1990) had been reached (i.e., the instance when information occurs so repeatedly that the researcher can anticipate it).

Krueger (1994) suggested that it is ideal for the focus group to have a moderator team; however, for this study the single researcher or moderator approach was used. The decision to use a single-person approach to gather focus group data is contrary to the best advice of researchers (Stage \& Manning, 2003). In addition, the researcher used "field note" strategy to record observations and interpretations about body language, tone, and group dynamics among participants immediately following each session (Merriam, 1998). George (2011) noted that a focus group analysis is unique in that the data will evolve throughout the process, and students' responses are likely to influence other students in some way. In analyzing the data, although students may have responded to a question, the information they provided may have been more appropriate in answering another question. Thus, the researcher had to decide where the information best fit. Proper notations were made in order to ensure that the data was woven in a 
way to report accurate findings. The researcher used a thematic approach in reporting the results. Thematic content analysis is a conventional method that involves looking at common patterns in participants' responses (Creswell, 2012).

The researcher thematically analyzed the data using an analytical five-phased cycle, which consisted of compiling, disassembling, reassembling, (and arraying), interpreting, and concluding (Yin, 2016). Disassembling of the data from participants' transcripts was accomplished using open coding to create category codes. According to Yin (2016), coding is the assignment of simple words or short phrases to capture the meaning of a larger portion of (the original) textual or visual data" (p. 334). Using the participants' transcribed data, initial words and phrases that were relevant to the study were identified. Words like "problems," "culture," "resources," "stereotypes," "racism," "success," "network," and "support" were highlighted throughout all participants' transcribed data. Key phrases such as "ask my professor for help," "it was good to have Black male mentors," and "self-motivation and supportive family members are the key to success," were noted throughout the participants' responses to the questions on the questionnaire and the interview protocol used during the focus group meetings and follow-up interviews.

\section{Data Analysis}

Data analysis began with compiling and transcribing each audio recording and uploading the transcripts to NVivo, a software used for qualitative analysis. Also, during the compiling phase, participant demographic information was organized to create a profile for each participant. The demographic information included participants' age, academic classification, major, and grade point average. To maintain confidentiality and anonymity, an alias was assigned to each participant. The process of disassembling is what is traditionally known as coding. Using NVivo, an open coding scheme was applied to the focus groups transcripts looking for data that addressed research questions one and three.

Specifically, for research question one the researcher looked for descriptive words, such as network, support, success, rewarding, graduate, retention rate, family resources, used by participants to describe their experiences in the 4A program. For research question three, a search was conducted to look for descriptive words such as Black, community issues, barriers, expectation, mental health, relationships, systems, that described staff members' perceptions for their interaction with the 4A participants. To explore research question two, priori codes from theoretical framework, nigrescence theory (Cross, 1991) was used to code the student participant focus group transcripts, which represented five stages of Black cultural identity development. In the reassembling phase, the researcher looked for related to one another to generate theoretical understanding of the social phenomenon in terms of the research question two.

\section{FINDINGS}

The researcher identified several themes focusing on how African American males achieved academic success in the $4 \mathrm{~A}$ program at a particular community college in the Mid-Atlantic region. Factors included faculty relationships, support both academic and emotional, cultural awareness and exposure, and value of mentoring academic advisors, and counselors. 


\section{Theme 1: Faculty Relationships Support both Academic and Emotional Needs}

The participants' experiences confirmed that faculty-student relationships promoted academic success and persistence. Some of the participants indicated that they had positive rapport with faculty.

Participants 3 and 5 stated, "They had some issues interacting with their instructor." However, with the exception of participants 3 and 5 the remaining three participants noted that their instructors were helpful. Participant 1 , one of the group members indicated, "We often discussed the problems we had with some of the instructors and ways we could cope with the problems."

Collectively, most of the faculty took time to learn about the students in the $4 \mathrm{~A}$ program. Therefore, most of the faculty tried their best to be supportive of the students. Three participants provided specific examples of how the faculty assisted them to persist in college, such as, offering extra credit, tutoring, and peer tutoring.

Participant 4 indicated, "It would have been hard passing some of my classes without taking my advisor's advice to ask my professors for help. In the past I was reluctant to seek their assistance."

Participant 6 indicated, "I received a lot of help from my instructors and tutors. It was good to know that support provided by the program, included tutoring, academic advising, particularly one-on-one advising, was paramount to my individual success."

Three participants provided specific examples of how 4A assisted them to persist in college. Participant 5 had a similar experience with his instructor. He commented, "My instructors recognized the fact that I really wanted to make it and went out of their way to help me, so I have had extremely positive experiences in the program." Participant 6 indicated, "I received a lot of help from my instructors and tutors. It was good to know that support was available when I needed it most." Both participants agreed that the support provided by the instructor, included tutoring, academic advising; particularly, one-on-one advising, was paramount to their individual success.

Some of the benefits identified by Focus Group 2 included improved grades, stronger relationships among faculty and students, and a feeling of academic and social support from school personnel. Participant 7 indicated that although the program was valuable, more attention should be devoted to faculty relationships, counseling, educational services, and employment opportunities after graduation. The group agreed with Participant 7 assessment of the 4A program.

Focus Group 3 consisted of seven African American men who discussed a number of advantageous of the 4A program. Specifically, participants identified the major benefit of the program was that it provided additional academic support they needed to succeed. Another benefit was that the program guided them through their respective majors. Focus Group 3 also emphasized that although the $4 \mathrm{~A}$ program was culturally supportive, it did not address racism and other societal problems faced by African American males.

Participant 8 noted, "It would take more than one program to help us address faculty relationships on campus." Overall, the three focus groups indicated that they had mixed experiences with faculty. Additionally, they concurred that their experiences were beneficial to them academically. The benefits they received were adequate in helping them cope with the academic challenges. 


\section{Theme 2: Cultural Awareness and Exposure}

\section{Pre-encounter}

Focus Group 1 consisted of six participates who described their cultural identity experiences. Participants 13 and 14 grew up in rural areas and attended an all-White high school. Participants 13 and 14 stated, "For the first time in their lives they felt being Black was less important because they were surrounded by White people." Participants 1 and 2 noted they had a similar experience. "We went to an all Black high school and the majority of our teachers were White." Participants 13 and 14 noted: "They didn't teach us a lot of Black history, only Harriet Tubman and Martin Luther King."

Participant 13 said, "You know I did everything White. I felt being Black wasn't important because I did everything White, like listen to their music, dated White women." Participants: "WOW!" Participant 2, "I experienced being talked down to by my instructors. It seems being White was more important." The White teachers would always talk [negatively] about us, especially when my friends would act up in class." Participant 4 and 5 indicated, "I grew up in the inner city where I was racially profiled by the police who were majority White." Participant 5 stated, "When trying to clear my name concerning the racial profiling everyone was White, from the police to my public defender and judge. It seemed they [were] against the Black race."

Participant 4 indicated, "Man it's not just White people. When I started classes, two of my teachers were Africans, and they treated me as if I was a second-class citizen."

Participant 4 noted, "There was time when my math teacher talked to me like I was nobody who was from Africa."

Focus Group 2 consisted of seven participates who described their cultural identity experiences. Participants $8,9,12$, and 15 noted that they felt like giving up on their race because they saw Johns Hopkins Hospital take over their East Baltimore community and no Black politicians came to support them. Participate 8 indicated, "A school was built for the staff of Johns Hopkins to send their kids, and unfortunately it didn't work out because none of the staff from Hopkins sent their kids." Participant 10 noted, "White privilege." Participant 11 said, "Coming from Cecil County that's all I saw was White people and at [that] time I had hate for my race because of all the racism I experienced." Participant 17 stated, "Yo, I agree with participant 11 because the doors were always slammed in my face. I wondered if I was White would I be in this situation."

Participant 8 noted, "I'm a veteran and being the oldest in the group being in the military I was always treated [differently] along with my friends and we often said at time[s] we wanted to be White because of the treatment we experienced." "We did black face; you know we put White paint on our face[s]."

Focus Group 3 consisted of seven participants who described their cultural identity experiences. Participants 3, 6, 7 indicated, "They felt the only way they could be successful was to be like their White friends." Participant 3 noted, "The White kids seem to get the better grades." Participant 7 stated, "It's crazy when you see the names of people who make the honor roll and [expletive deleted] like that Whites or other foreign people Africans other than a small amount of us Black students."

Participant 16 noted, "It's not just White people, you know people from India, the Africans, some Spanish people, they are all in my class." Participant 18 stated, "It's mostly women." Participants 19 and 20 concur, "They are the majority in my classes." 


\section{Encounter}

Focus Group 1 consisted of six participants who described their cultural identity experiences. Participant 1, 2, 4, 5, 13, 14 noted that, "The election of Barack Obama shed light of on being a Black man." Participants 4 indicated that, "It was a great feeling to see a Black man in the White House." Participant 13 concurred, "I felt great. It inspired me to be successful in the 4A program."

Participant 14 said, "The killing of Freddie Gray opened my eyes to be successful in this program because in my heart it was the White police who killed him. It could have been me. I have kids. It's up to me to be successful not only in this program, but out in these streets."

Participants 1 and 2 indicated, "You know the Tavon Martin killing made me wake up." Participant 2 stated, "That could be me. I live in a diverse neighborhood, poor and middle class. I don't want to be a body (slang for killed). These killings have woke me up to be a better Black man. We have to strive for better."

Participant 5 noted, "What they are trying to do to Bill Cosby [allowed] me to see no matter how successful you are, someone is trying to knock you down." As a race we have to stick together and not do harm to one another."

Participant 4 indicted, “OJ, who embraced White people, I don't think if he would have associated himself with Black people he would not be in jail."

Focus Group 2 consisted of several participants who described their cultural identity experiences during the encounter stage; however, many of the participants in focus group had similar experiences as it relates to the encounter stage. Participant 9 indicated, "The Black Lives Matter movement assured me that being Black was okay. It reminded me of the Civil Rights Movement that occurred in the sixties."

Participant 10 noted, "The second term of Barack Obama showed that whatever you want to do in life as a Black person, you can do it."

Focus Group 3 consisted of similar examples. Participants 3 and 7 stated, "The rioting of Baltimore City Public school students during the Freddie Gray ordeal showed people have had enough of unfair treatment."

Participant 16 indicated, "The killing of nine church goers at Mother Emmanuel in South Carolina showed me the importance of being Black."

\section{Immersion/Emersion}

Focus Group 4 consisted of several participants who described their cultural identity experiences with their mentor as Afro-centric, helpful, warm, and understanding. Participants 9 indicated that his mentor "would always encourage me to read books about my culture when we met at the library."

Participant 15 stated, "My mentor insisted that I join a social justice organization, such as, the NAACP, Urban League that advocated Black causes.” Participant 14 stated, "Because I came from a rural area I seldom read about my Black culture. Nevertheless, [I] watched Black shows; however, many of the lectures that the 4A [program] provided was from Black people. One person that caught my attention was David Miller. He talked about W. E. B. DuBois who was a civil rights activist. I was never taught about him." Participant 13 commented, "My mentor and I went to several social justice rallies, particularly the one about police brutality." Participant 8 noted, being a part of the 4A program would lead to success for him. 


\section{Internalization}

Focus Group 4 consisted of several participants who described their cultural identity during the internalization stage. Participants 7 and 10, who were raised in the suburbs noted, "Because of the racism we experienced by White people, we no longer hold any ill feelings toward them."

Participants 11, 13, and 14 were raised in rural areas and they concurred. Participants 11 and 14 stated, "Being in the 4A program allows us to forgive what we experienced and embrace how we feel about ourselves."

Mentor 1 noted,

I was relatively pleased with the feedback I received from the $4 A$ students. I not only saw a major improvement in some of their grades, but I also noticed that their attitudes toward the college had changed. Some of my mentees were disgruntled with the system. They were not aware of academic tutorial, they had difficulty balancing work and classwork, and they felt that neither the college nor society is interested; at least three of my five mentees had a different impression of college and the resources that were available to them.

Mentor 2 indicated,

Higher education has not always been kind to African American men. For years, we have seen a decrease in their rate of participation. I think that our influence on their lives is remarkable. I also think that their overall academic performance has improved. The mentors we have on board have been able to help them find resources they didn't know existed. Look around, and you'll find our mentees in the library, in tutorial labs, participating in work-study programs and participating in cultural and social activities. They have a positive attitude towards learning and themselves.

\section{Internalization-Commitment}

Finally, in the fifth stage, internalization-commitment, the person is a social activist, in the sense that actions taken for "the cause" follow from beliefs about Blackness that have been developed throughout the stages. People in this stage may devote "an extended period, if not a lifetime, to finding ways to translate their personal sense of Blackness into a plan of action or a general sense of commitment" (Cross, 1991, p.220). These five stages come together in a theoretical framework that is applicable to the researcher's PK-20 educational experience and is integral to the development of his current role as an educational leader.

Though the stages of the nigrescence model may appear linear, Parham (1989) explored whether individuals follow the stages of the model in strict sequence. His research, which Cross was engaged in as original developer of the nigrescence model, has revealed that it is indeed possible for individuals to cycle through some of the stages of the model more than once.

\section{Theme 3: Value of Mentoring, Academic Advisors and Counselors}

In Focus Group 4 all participants indicated during their interviews that they recognized the value of mentors, academic advisors, and counselors. Furthermore, most of the participants stated, "That their mentoring relationships were supportive because their mentor was the same race and gender." 
Participant 20 noted, "Having a mentor that is like you offers a perspective from a future standpoint that you may not see right now. For example, if I was a mentor, I'm 60 years old and I have a 19-year-old mentee. I'm going to provide wisdom in a few things that he might not know. So, when he gets to that age possible he will understand." One group member, Participant 9, indicated, "My mentor went through some of the things I went through. He knew that there are only a few Black males on this campus, and an open mind was needed to address their needs."

Participant 10 said, "It was a good idea to have Black male mentors who understood the problems I faced trying to make it." These issues or problems may include, but are not limited to stereotyping, experiencing subtle and overt racism and being burdened by outside distractors.

Participant 11 responded, "I guess you can say that his support was important in many ways." He also indicated, "I do think my advisor should have devoted more time to assisting me though. It was difficult scheduling a time to meet with them because they were always doing something else." All participants identified their relationship with advisors and counselors as helpful, but three of them did not feel as though their support was essential to their success. Participant 12, for example said, "I applied myself." He indicated, "I benefited from my advisors' advice, but I would have eventually found a way to make it even if 4A did not exist."

Participant 2 felt that the 4A program did not provide the personal counseling he expected. Participant 8 noted, "Balancing work and school, for instance, was a problem for me, and counselors did not address this issue. In fact, I am not sure they could have helped me." Focus Group 3 agreed that mentors, advisors, and counselors were supportive among the seven participants. Five of the participants spoke positively of the mentors they were assigned. However, two of them did not feel that mentors had adequate time to address their academic, personal, and social issues. Participant 8, commented, "The mentors had too many other things to do. I think they meant well, but it was too time consuming for then."

Support from mentors, advisors, and counselors may have been the single most important factor that contributed to the success of African males in college. According to one participant, Participant 12, "When you know that someone is in your corner, it makes a world of difference. I would have succeeded on my own but having the support of advisors and counselors gave me greater self-confidence."

Participant 16 also shared his thoughts on the value of his mentor. Participants 16, 18, 20 all agreed during their interviews that they saw value in having a mentor of the same race and gender, but they provided their own explanation on why they felt the need should be on the experiences of the participant situation.

Participant 18 noted. "My mentor understood my struggles because he had similar struggles." Participant 16 indicated: "I came from a fatherless environment; I wanted to get a feel for a father figure and see if we could build a relationship."

Participant 20 stated, "It felt good to see someone who had already obtained several degrees, which led me to be successful in the 4A program."

Counselor 1 underscored this belief:

Many African American males attend college with a lot of baggage. Some of them are from low-income families that depend of them for financial support. Going to college is a major decision that impacts the entire family. I have found that $4 \mathrm{~A}$ participants have some of the same problems found among most African American males in society in general. My job is to help them address personal issues that are 
barriers to learning. I can say that I have had a tremendous influence on African American males' behaviors, attitudes, and success rate because the problem lies within society. In other words, racism, profiling, and negative perceptions of African American males exist in society and spill over into college campuses. "The time I spend with students is supportive, but they need more than support from me to make a real difference. There is no question in my mind that their personal and social problems cannot be adequately addressed in the short time I spend with each of them.

Similar feedback was provided by Counselor 2 who indicated:

My goal was to provide personal counseling that would make a difference in the lives of 4A students. I realized from the beginning that many of their issues were due to their adverse family circumstances. It was difficult addressing their problems because in many ways their problems were not college related, but society related. In fact, some of them saw themselves as victims of society. I always felt that the odds were against them as well, but they could overcome many obstacles in society by working hard and taking the advice of staff members who understood their circumstances. I can't honestly say that I had a major impact on their lives because my participants did not always want to express their frustration or disappointment with society. This made my job challenging.

Both counselors indicated that although their services were supportive of $4 \mathrm{~A}$ participants as they matriculated in college, problems faced by the many of 4A participants were evidence of larger problems in society. It is important to note that participants of 4A concurred with this statement during their discussions. Advisors, mentors, and counselors seemed to recognize their own deficiencies in attempting to redress student issues based on race and ethnicity. The researcher was somewhat surprised to learn of such reflection on the part of this advocacy group, but nonetheless was impressed by their honesty. The two advisors who participated in the focus group had similar perceptions of their influence in the success of African American male 4A participants. However, both advisors addressed the various services that were provided.

Specifically, Advisor 1 said:

So, I guess it can be said that I influenced the success of some advisees, but other advisees didn't get the message or chose not to do what was in their best interest. Perhaps having more time to monitor and follow-up with participants would have yielded better results. There were times when it was difficult getting students to do what was expected of them. In fact, meeting timelines for financial aid, registering for classes in a timely manner, and seeking academic assistance when deficiencies were first noticed were major challenges. Far too often my advisees failed classes because they did not take deadlines seriously. I feel that I influenced the behaviors of some of my advisees, but there were others who did not take college seriously.

Advisor 2 asserted:

Getting students to meet timelines and follow college polices is no easy task. Many $4 A$ participants are not accustomed to being in a structured academic environment, so it's difficult trying to change their behavior. I am not sure I had a tremendous influence on their attitudes or behaviors, but some of participants were able to finds ways to meet their goals. I feel that having more opportunities to 
closely monitor participants' progress would give advisors greater influence over their access success.

The two advisors who participated in the focus group had similar perceptions of their influence in the success of African American male 4A participants. However, both advisors addressed the various services that were provided.

\section{DISCUSSION}

The four focus groups that participated in this study described their experiences in $4 \mathrm{~A}$ as academically and culturally supportive. Moreover, they indicated that the program helped them to build positive relationships with faculty members. These revelations are not surprising in that research has consistently shown that when African American males are afforded opportunities to engage in meaningful academic and social activities with mentors and other staff, they are more likely to be successful in college. Specifically, in-class discussions, peer interactions, and faculty-staff mentoring play a key role in student success on the undergraduate level, especially for African American males (Strayhon \& DeVita, 2010). Most of the participants had positive comments about the 4A program. However, they insisted that more effort should have been devoted to helping African American male students deal with campus racism, which they perceived to be indicative of societal racism in general. African American males' concern about racism on college campuses, in particular, is nothing new, for some scholars have theorized that racism has traditionally been a major factor negatively impacting African American males' persistence in college (Harper, 2015). Harper (2016) studied academically-successful African American males on nearly 30 campuses across the United States and found that all but two of the African American males had experienced racism in some form at a predominately White institution.

Participants' responses also revealed that there was a profound appreciation for the services offered by 4A. However, many participants felt that they would have been successful without the services. That is, such factors as internal motivation, family influence, academic preparation, etc. may have played an even greater role in student success than the $4 \mathrm{~A}$ program. Many student support programs similar to $4 \mathrm{~A}$, have a moderate impact on student retention. Given the fact that African American males are grossly underrepresented in higher education, a moderate impact may be perceived as a major achievement. Particularly noteworthy was that the focus groups commonly expressed overwhelming support for 4A. Participants felt comfortable with their mentors and praised their efforts to provide a warm environment. However, it was not clear as to whether the participants felt that mentors had enough clout to make a significant difference. That is, some of the problems faced by participants, such as balancing academics with employment and overcoming personal barriers, were not adequately addressed by $4 \mathrm{~A}$. In fact, it was not clear as to whether the participants felt that $4 \mathrm{~A}$ had the capacity to address such issues.

As noted in Chapter 2, the experiences of African American males and the role that community colleges play in mentoring and guiding their success can best be examined using the nigrescence theory - the process of becoming African American. The Pre-Encounter stage of the nigrescence theory stipulates that a stigma is placed on African American males upon enrolling on college campuses. African American males perceive White culture as privileged compared to other cultures. As a result, they become disassociated with White culture and closely attach to their own culture. During the focus group interviews with 4A participants, the topic of racism on college campuses and society in general, was a major concern. In fact, many 
of the participants perceived racism to be a major obstacle to their success in college. Students complained that little or nothing had been done to eradicate racism. The frustration of functioning in a racist environment was depicted by Participant 5 who argued that "People don't see what Black males see and experience. Some of the mentors were able to understand our experience with racism, but they couldn't do anything about it." There was no evidence in the focus group that racism was effectively addressed.

Participant 5's comments are not uncommon. In fact, Harper (2015) noted that African Americans have been victims of college racism for many years, and college administrators have not been successful in addressing the problem. Institutions of higher learning must find ways to teach African American males to effectively respond to and resist racist stereotypes upon enrolling in college (Harper, 2015). Such strategies may include teaching African American males effective stress management strategies and conflict resolution skills needed to work successfully with other students, faculty, and members of society (National Network to Eliminate Disparities, 2014).

The Encounter phase of the nigrescence theory indicates that African Americans begin to question worldviews, their feelings about racial conditions in society, and the state of African American culture. One participant, Participant 7, did not feel that that the A program was effective in addressing racism. This was reflected in his statement that, "It would take more than one program to help us address racial barriers in higher education." During Stage 2, there is a need to engage African American males in meaningful conversations with mentors and counselors to improve their self-esteem, social skills academic performance (Giordano, 2012). Giordano noted that college mentoring can play an essential role in increasing the likelihood that African American male community college students will transfer for 4-year institutions of higher education (2012).

The Immersion/Emersion operational phase of the nigrescence theory is the African American pride stage. In this component, African American males struggle to maintain a positive cultural identity. Mentors, advisors, and counselors could play a key role by exposing African American males to social activities that lead to academic success. Indeed, the 4A organization is an example of a social program designed to support African American males. However, there is a need for other organizations, such as the National Action Council for Minorities in Engineering (NACME) and Science, Technology, Engineering, and Mathematics (STEM) to act as catalysts to increase African American male participation in higher education (National Action Council for Minorities in Engineering, 2013). When multiple opportunities are afforded to them before or during Stage 3, they become inspired and better able to navigate on college campuses.

The Internalization stage is the point at which African American males feel confident about their skills and proud of their cultural heritage. Mentors, advisors, and counselors in 4A who effectively addressed the needs of African American males were likely to realize positive outcomes. However, their inspiration did not always appear to come from their mentors, advisors, of counselors in the 4A program. Participant 8 illustrated this point when he stated, "My mother is my most important mentor. The mentor assigned to me in 4A was helpful, but I can't say that I would have failed if he had not been assigned to me." Additionally, Participant 12 indicated, "Self-motivation and supportive family members are the key to success."

In answering RQ3, both counselors agreed with 4A participants. Both counselors revealed that their influence on the success of African American males was limited and more interactions were needed in order to have a significant influence on their success. This revelation is nothing new in higher education. Gibson (2014) indicated that although institutions of higher learning have implemented a number of interventions to influence the 
academic success rate of African American males, many African American males continue to experience failure and isolation, and eventually lose interest in attaining a degree. Moreover, they struggle with external obligations that interfere with their persistence. Avery illustrated this point when he asserted, "Balancing work and school, for instance, was a problem for me, and counselors did not address this issue. In fact, I am not sure they could have helped me."

The Internalization-Commitment stage consists of African American males who develop a plan to live with their Blackness as they persist in college. An effective 4A program plays an essential role in encouraging African American males to engage in academic and social activities that contribute to their growth and development. Examples of such programs include tutorial programs, technology labs, clubs and organizations related to their majors, and service learning. Participants in $4 \mathrm{~A}$ had mixed feelings about the value of the program. Although many of the students in the focus groups contended that their experiences in $4 \mathrm{~A}$ were positive, they did not all agree on the effectiveness of the program because personnel were not always available to assist them. Participant 18 expressed this concern when he commented, "They had too many other things to do. I think they meant well, but the job was too timeconsuming." Harper (2015) lamented that colleges should devote more attention to addressing the needs of African American males who continue to face academic challenges in college.

\section{Limitations}

One primary limitation of the study was the small number of students who participated from the available pool. This sample was selected because of its existing membership in the school population and their ready availability; however, not all African American males matriculating at the school participated in the 4A Program. A second limitation of the study was the inability to generalize findings to the larger population of African American male community college students given the small size of this non-random (non-probability) sample. A third limitation is the lack of comparability of program outcomes to similar programs. The capacity to compare programs lends more rigor to the overall design and the strength of outcomes.

\section{FUTURE RESEARCH}

Working with African American males in higher education has provided the researcher with the opportunity to examine factors that impact their persistence. Student support programs, such as $4 \mathrm{~A}$, provide a critical pathway to success for African American males who may otherwise choose to pursue endeavors that do not include a college education. In an effort to gain insight into ways to increase the success rate of African American males, the following research recommendations are made:

- A study should be conducted that examines the impact of personal counseling on the success rate of African American males. Participants in each focus group discussed difficulties they faced with racism and balancing college demands with employment.

- A longitudinal program evaluation is needed to determine the effectiveness $4 \mathrm{~A}$ and similar African American male programs developed for the purpose of improving retention in higher education.

- A quantitative study is required to survey the needs of African American males upon entering college. Having knowledge of the needs of African American males can help inform college support personnel of these needs of these students. 
- A study is necessary to determine the impact of specific support services (e.g. tutoring, library assistance, remedial instruction, and technology) in improving the success rate of African American males.

- A phenomenological study is needed to understand the meaning of the learned experiences of African American males in 4A and similar programs.

- There is also a need to conduct a similar study in two-year technical colleges, four-year colleges and universities to determine the similarities and differences in their academic needs. Additional data is needed to determine best practices needed to increase the success rate of African American males in higher education.

- An ethnographic study is needed in which the researcher studies an intact cultural group in a natural setting over prolonged period of time by collecting, primarily, observational data (Creswell. 1998).

\section{REFERENCES}

American College Association, Inc. (2010). What works in student retention? Fourth national survey. community colleges with twenty percent or more Black students enrolled. ACT, Inc., 26. (ED515407).

American Council on Education. (2006). Minorities in higher education annual status report: 2006. Washington, DC: Author.

Azibo, D. A. (1983). Some psychological concomitant and consequences of the Black personality. Journal of Non-White Concerns, 11(2), 59-66.

Baker, M. J. (Summer 2007). Cross-cultural mentoring in institutional contexts. Negro Educational Revie, 58(1-2), 85-103.

Beckles, W. A. (2008). Redefining the dream: African American male voices on academic success (Doctoral dissertation). Available from ProQuest Dissertations and Theses database. (UMI No. 3314150).

Brown, R. (2009). Perceived influence of African American males mentorship on the academic success of African American males in predominately White institution of higher education: An institutional case study. National Forum of Multicultural Issues Journal, 6(4), 317-339.

Burrow, A.l., Tubman, J. G., \& Montgomery, M. J. (2006). Racial identity: Toward an integrated developmental psychological perspective. Identity: An International Journal of Theory and Research, 6(4), 317-339.

Bush, E. C. (2004). Dying on the vine: A look at African American student achievement in California community colleges (Doctoral dissertation). Available from ProQuest and Theses database. (UMI No. 3115605).

Bush, E. C. and L. Bush. (2010). Calling out the elephant: An examination of African American male achievement in community colleges. Journal of African American Males in Education, (1), 4062.

Carter, R. T. (1991). Racial identity attitudes and psychological functioning. Journal of Multicultural Counseling and Development, 19, 105-114.

Carter, R. T., Pieterse A. L., \& Smith, S. (2008). Racial Identity status profiles and expression of anger in Black Americans: An exploratory study. Journal of Multicultural Counseling and Development, 36(2), 101-112.

Creswell, J. W. (1998). Qualitative inquiry and research design: Choosing among five traditions (2nd ed.). Thousand Oaks, CA: Sage.

Cross, W. E., Parham, T. A. \& Helms, J. E. (1991). The stages of Black identity development: Nigrescence models. In R. L. Jones (Ed.), Black psychology (pp. 337-393). Thousand Oaks, CA: Sage. 
Dabney, R.M. (2012). An exploration of African American male community college students', experiences concerning their successful post-secondary enrollment (Unpublished doctoral dissertation). Available from ProQuest and Theses Database. (UMI No. 3546753)

Dellums Commission. (2004). A way out: Creating partners for our nation's prosperity by expanding life paths young men of color. Washington, DC: Joint Center for Political and Economic Studies, Health Policy Institute.

Dickens, M. (January 2012) Beyond statistics: African American male persistence in community college. ProQuest LLC.

Edelman, P., Holzer, H., \& Offner, P. (2006). Reconnecting disadvantaged young men. Washington, DC: Urban Institute Press.

Evans, N. J. (2010). Student development in college: Theory research, and practice (2nd ed.). San Francisco: Jossey-Bass.

Faison, A. C. (1993). The effect of autonomy and locus-of-control on the academic achievement of Black male community college students (Doctoral dissertation). Available from ProQuest. (UMI No. 9315460)

Feagin, J. R., Vera, H., \& Imani, N. (1996). The agony of education: Black students At White colleges and universities. New York: Routledge.

Fletcher, M. (2013, July). Minority and Whites follow unequal college paths. The Washington Post. Retrieved from http://articles.washingtonpost.com/2013-07-31/Business/40910009_1_newreport-colleges-postsecondary-system

Flick, U. (1998). An introduction of qualitative research (5th ed.). Thousand Oaks, CA: Sage.

Freeman, T.L. (2003). Theoretical model for studying year-to-year persistence of two- year college students by ethnicity using the beginning postsecondary students longitudinal study 1996-98. Dissertation Abstract International. (UMI No. 3094695)

Gardner-Kitt, D. L., \& Worrell, F. C. (2007). Measuring nigrescence attitudes in school-aged adolescents. Journal of Adolescence, 30, 187-202.

George, T. C. (2011). Projection of African American males on retention (Unpublished doctoral dissertation). Western Kentucky University, Bowling Green, Kentucky.

Gibson, M.A. (2014). Minority status and schooling. A comparative study of immigrants and involuntary minorities. New York, NY. Garland.

Giordano, R. (2012). Mentoring effects make a difference. Community Colleges use personal guidance to keep African American male students engaged. The Philadelphia Inquirer. Retrieved from http://articles.philly.com/2012-04-22/news/31382662_1_students-aim-african-Americastudents-young-black-men.

Glenn, F. S. (2003). The retention of Black male students in Texas Public Community College. Journal of College Student Retention: Research, Theory and Practice, 5(2), 115-133.

Gray, K. (2011). Deviant bodies resisting online: Examining the intersecting realities of color in Xbox Live. Dissertation \& Theses (Publication No. AAT 3452875) Available at: http://respository.asu.edu/items/9027

Greene, T. G., Marti, N. C., \& McClenney, K. (2008). The effort-outcome gap: Differences for African American and Hispanic community college students in student engagement and academic achievement. Journal of Higher Education, 79(5).

Hampton, P. (2002). Academic success for African American male community college students (Doctoral dissertation). Available from ProQuest and Theses database.

Harper, S. R. (2006). Peer support for African American male college achievement: Beyond internalized racism and the burden of acting White. Journal of Men's Studies, 14(3), 337-358.

Harper, S. R. (2014). (Re)setting the agenda for college men of color: Lessons learned from a 15-year movement to improve Black male student success. In R. A. Williams (Ed.), Men of color in higher education: New foundation for developing models for success (pp. 116-143). Sterling, VA: Stylus.

Harper, S. R. (2015). Making engagement equitable for students in the U.S. higher education. In S. R. Harper (Eds.), Student engagement in higher education: Theoretical perspectives and practical approaches for diverse populations (2nd ed., pp. 1-14). New York: Routledge. 
Harper, S. R. (2016). Surprise, sensemaking, and success in the first college year: Black undergraduate men's academic adjustment experiences. Teacher's College Record, 118(6), 1-30.

Harper, S. R., \& Quaye, S.J. (2007). Student organizations as venues for Black identity expression and development among African American male student leaders. Journal of College Student Development, 48(2), 127-144.

Hughes, R. L. (2010). Engaging African American males for educational success. Gifted Child Today, $33(2), 55-60$.

Ihekwaba, R. H. (2001). A comparative analysis of African American male and female students' perceptions of factors related to their persistence at a Texas community college (Unpublished doctoral dissertation). University of Texas, Austin, Texas.

Johnson, B. (2010). Student-faculty membership outcomes. In T. D. Allen \& E. Lit (Eds.), The Black handbook of mentoring (pp.189-210). Oxford, UK: Blackwell.

Jordan, P. G. (2008). African American students' success in an urban community college: A case study (Doctoral dissertation). Available from ProQuest and Theses database. (UMI No. 3311541).

Kolesnikova, N. (Fall 2009). The changing roles of community colleges. Bridges. Retrieved from http://www.stlouisfed.org/publications/br/articles/?id=1699.

Krueger R. A. (1994). Focus groups: A practical guide for applied research. Thousand Oak, CA: Sage.

Lincoln, Y., \& Guba, E. G. (1985). Naturalistic inquiry. Newbury Park, CA: Sage.

Mason, H. P. (1994). The relationship of academic, background, and environmental variables in the persistence of adult African American male students in an urban community college (Doctoral dissertation). ProQuest Dissertation and Theses. (UMI No. 9430242)

Mangan, K. (February 2014). Minority male students face challenge to achieve at community college. Chronicle of Higher Education. Retrieved from http://chronicle.com/article/Minority-MaleStudents-Face/144979/.

Merriam. S. B. (2001). Qualitative research: A guide to design and implementation. San Francisco: Jossey-Bass.

Mosby, D., Esters, L., Robinson, M., \& Beckles, W. (2009). The Sankofa Initiative promoting student success for African American males in community college: A preliminary discussion. Retrieved from http://www.morgan.edu/Sankofa/index.asp

Morgan, D. L. (1997). Focus groups as qualitative research (2nd ed.). London: Sage.

Nunez, E. (2013, February). Improving completion rates of minority community college students transferring to 4-year colleges. Huffington Post. Retrieved from http://www.huffingtonpost.com/elsa-nunez/improving-completion-rate_b_2625751.html

Owens, D., Lacey, K., Rawls, G., \& Holbert- Quince, J. (2010). First-generation African American male college students: Implications for career counselors. Career Development Quarterly, 58(4), 291 300.

Parham, T. A., \& Helms, J. E. (1985). Attitudes of racial identity and self-esteem of Black students: An exploratory investigation. Journal of College Student +Personnel, 26(2), 134-147.

Perrakis, A. I. (2008). Factors promoting academic success among African American and White male community college students. New Directions for Community College, 142, 15-23.

Riley, N. M. (2007). A steady drop will wear a hole in the rock: Feminism, the John Henry Myth, and the Black male experience in higher education: A persistence case study (Doctoral dissertation). ProQuest Dissertations and Theses database. (UMI No. 3291817)

Rosenberg, M. (1979). Society and the adolescent self-image. Princeton, NJ: Princeton University Press.

Sellers, R.M. (1998). Racial ideology and racial centrality as predictions of African American college students' academic performance. Journal of Black Psychology, 24, 8-27.

Sellers, R. M., Smith, M., Shelton, J. N., Rowley, S., \& Chavous, T. M. (1998). The multidimensional model of racial identity: A reconceptualization of African American racial identity. Personality and Social Psychology Review, 2, 18-39.

Scaggs, S. L. (2004). The retention of Black male students at Mississippi public community and junior colleges: Identifying best practices in rural Mississippi community colleges (Doctoral dissertation). ProQuest Dissertations and Theses Database. (UMI No. 3120822) 
Scott, L., Jr. (2003). The relation of racial identity and racial identity and racial socialization to coping with discrimination among African American adolescents. Journal of Black Studies, 33(4), 520538.

Schott Foundation for Public Education (2010). Yes we can: The Schott 50 State Report on Public education and Black males. Retrieved from http://www.blackboysreport.org/breport.pdf

St. Louis Community College (2013). African American male initiative. Retrieved from http://www.stlcc.edu/Student_Resources/African-American_Male/index.html.

Strayhorn, T., \& Devit, J. (2010). African American males student engagement: A comparison of good practices by institutional type. Journal of African American Studies, 14(1), 87-105.

Thomas, A., \& Speight, S. (1999). Racial identity and racial socialization attitudes of African American parents. Journal of Black Psychology, 25(2), 152-170.

Tinto, V. (1993). Leaving college: Rethinking the causes and cures of student attrition (2nd ed.). Chicago: University of Chicago Press.

Walter, H. (2013). Together we cannot fail: Addressing the academic achievement gap for Black males. Center for Collaborative Learning. Retrieved from http://www.omgcenter.org/insights.

Wilkinson, S. (2004). Focus group research. In D. Silverman (Ed.), Qualitative research: Theory, method and practice (pp. 177-199). London: Sage.

Wood, J. L. (2011). Same...but different: Examining background characteristics among Black males in public 2-year colleges. The Journal of Negro Education, 82(1), 47-61.

Worrell, F., \& Gardner-Kitt., D. (2006). The relationship between racial and ethnic identity scale and the multigroup ethnic identity measure. Identity: An International Journal of Theory and Research, 6(4), 293-315.

Yin, R. K. (2016). Qualitative research from the start to finish (2nd ed.). New York: Gilford.

Zell, M. (2011). I am my brother's keeper: The impact of a Brother2Brother program on African American men in college. Journal of African American Males in Education, 2(2).

JOEL BRATTON, Dr. Joel Bratton Jr., is an Educational Specialist II for Baltimore City Public Schools. Joel's research focuses on Urban Education and the Achievement Gap. African American Male student success in K-12 and achievement gap in the community college, particularly social, psychological, academic, environmental and institutional. Dr. Bratton is the Founder and CEO of Projecthope Educational Consultants LLC; which provides educational services to school district throughout the country. 